\title{
Contribution to drift design using discrete fracture network modelling at the Éléonore Mine in Canada
}

\author{
M Grenon Laval University, Canada
}

A Landry Laval University, Canada

J Hadjigeorgiou University of Toronto, Canada

PL Lajoie Goldcorp Inc., Canada

\begin{abstract}
Discrete fracture networks (DFN) were used to model the structural regime around mining drifts at the Éléonore underground mine in Canada. The generated DFN models were subsequently used to investigate the creation of rock wedges along the drifts that may impact the stability of the excavations.

Photogrammetry tools were used to characterise the rock mass structural regime and provide the input data for the generated DFN models. The impact of the choice of employed DFN model on the analysis was investigated with reference to the stability of excavations. A series of parametric analyses demonstrated the sensitivity of the model to variations in the properties of the structural regime. The benefits of using stochastic modelling to capture the inherent variability are reviewed. The paper concludes with a discussion on the requirements for the appropriate implementation of the DFN methodology as part of a probabilistic design approach for mining drifts.
\end{abstract}

\section{Introduction}

Over the last decade, the use of DFN became widespread, partly because of recognition of their potential, and improved computer performance. Initially applied in hydrogeological and petroleum engineering applications, DFN are now an integral part of scoping studies and engineering design for several civil and mining projects. Nevertheless, DFN are rarely used in the design of mining drifts.

DFN modelling relies heavily on the quality of the input structural properties data gathered in the field. Traditionally, joint sampling methods rely on manual mapping of the rock face using scan lines or scan windows (Priest \& Hudson 1976; Pahl 1981; Kulatilake \& Wu 1984; Zhang \& Einstein 1998). These methods, although efficient in obtaining the structural properties of the rock mass, are time consuming and thus often overlooked in an operating environment such as a mine in production. The result is a relative absence of comprehensive field data that can be used for the design of geotechnical projects.

Over the last years, digital mapping techniques were used and validated in the field. These methods are based on the acquisition of point clouds on the rock surface through terrestrial laser scanning (TLS) or photogrammetry. This step is then followed by a numerical investigation of the fractures' geometrical properties using computer tools. Several authors discuss the merits and limitations of these mapping techniques (Birch 2006; Gaich et al. 2006; 2008; Kemeny et al. 2006; Haneberg 2008; Sturzenegger \& Stead 2009; Dubois \& Grenon 2012; Grenon et al. 2004; Sturzenegger et al. 2009).

This paper presents a case study at an underground hard rock mine in eastern Canada. Photogrammetry data were used to provide the input parameters to generate DFN models. The generated models were employed to explore their applicability in drift stability analysis. An investigation was conducted to demonstrate the influence of the choice of DFN model on the analysis and model sensitivity to the variability in the properties defining the structural regime. A discussion was presented on the requirements 
for the appropriate implementation of the DFN methodology as part of a probabilistic design approach for mining drifts.

\section{1 Éléonore case study}

The Éléonore Project is located in the James Bay region, on the shore of the Caniapiscau reservoir (Figure 1). It is one of the most important gold-bearing mining projects in development in Canada. Production begun during the last quarter of 2014 and is scheduled to reach 7,000 t/day.

The operation utilises a ramp access from the surface and two shafts 725 and 1,500 $\mathrm{m}$ in depth. The orebody is sub-vertical, and is exploited using the long hole mining method. Mining is planned to take place in two phases, the first one between the depths of 80 and $650 \mathrm{~m}$, and the second phase between 650 and $1,400 \mathrm{~m}$ (Lajoie 2013). The Éléonore Project is highly mechanised, and the hauling drifts and the draw points have a typical cross section of $5.5 \times 5.5 \mathrm{~m}$.

From a geological perspective, the Éléonore property is centred on the Ell Lake intrusion (a small diorite stock bordering the batholithic complex), and straddles the contact between the Opinaca metasedimentary sub-province and the La Grande volcano-plutonic sub-province.

The most common unit is metasomatised greywacke (more than 11 possible declinations), which is fine-grained and usually medium grey with a quartzofeldspathic matrix. Other major geological units include diorite, diabase, arenite, conglomerates and pegmatite dikes at a scale varying from small centimetric veins to metric dykes. The host rock in the mineralised zones is usually a thinly-bedded greywacke (SRK Consulting 2011).

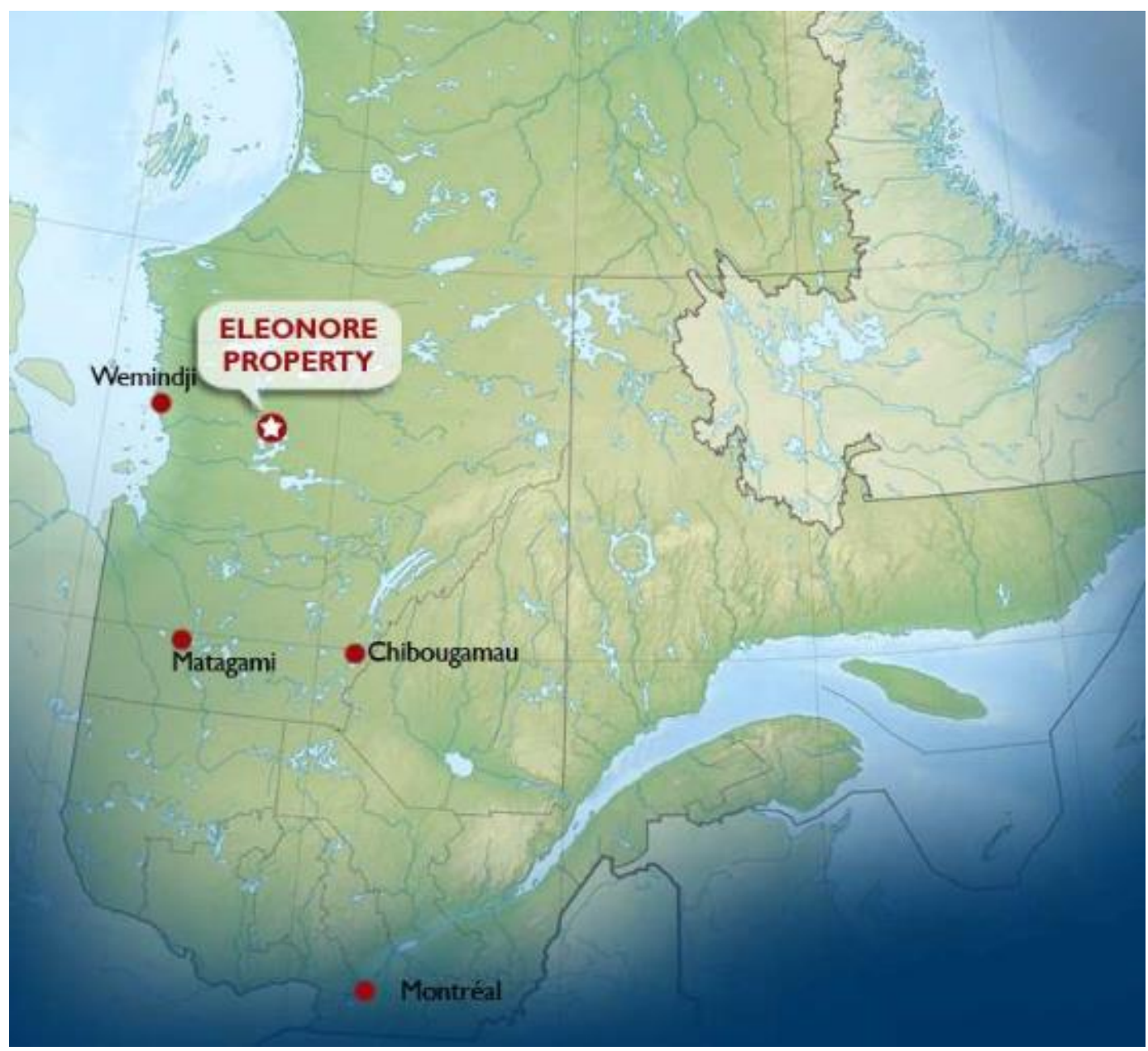

Figure 1 Goldcorp Éléonore Project location (Ministère de l'Énergie et des Ressources naturelles du Québec 2011) 
A strong presence of sub-horizontal fractures was observed from the surface down to $400 \mathrm{~m}$ below the ground. At greater depth, the intensity of this fracture set is less pronounced although it is still observed regularly. Sub-vertical fracture sets with various orientations were also observed at Éléonore (Golder Associates 2008).

\section{$2 \quad$ Field work}

A major challenge in an operating mine is collecting the necessary field date to characterise the rock mass. At Éléonore, the geomechanical data collection process made use of a commercially available 3DM analysis mapping suite ( $v$ 2.5.0) from ADAM Technology (2010). Digital images were taken during development of three rock faces and were used to construct a 3D numerical model of the rock mass in three mining drifts, Amn-0354, Gmn-0354-1s and Gmn-0357-1n. The drifts were at the 440 level within a radius of $50 \mathrm{~m}$ and at less than $10 \mathrm{~m}$ from the mineralisation (Figure 2). The general face orientation was $88^{\circ} / 252^{\circ}, 87^{\circ} / 185^{\circ}$ and $86^{\circ} / 161^{\circ}$ for the Amn-0354, Gmn-0354-1s and Gmn-0357-1n drifts respectively. The lithology was mostly composed of lightly metasomatised greywacke. A two-man crew took two hours to complete the field work at each face. This included the digital imagery and surveying.

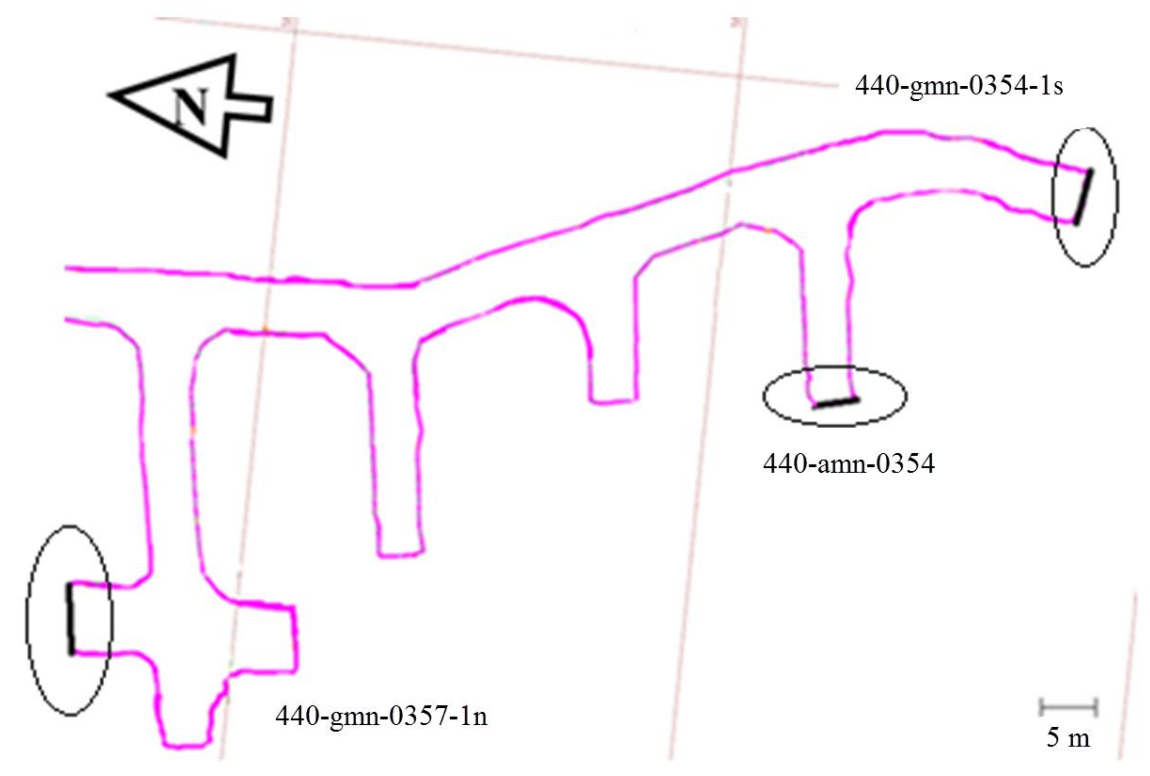

Figure 2 Location of the three development rock faces

\subsection{Model construction}

Twelve digital images were recorded in every drift. The 3D numerical models of the fractured rock mass were constructed using these photographs. The 3DM analyst was used to match similar points between the various pictures. A digital terrain model (DTM) was created for every drift. A synthetic surface was created from the DTM and the digital images were superimposed on the surface. It took less than two hours of processing, including file transfer and management, to construct the DTM for each drift. Figure 3 presents the DTM with superimposed pictures for two drifts.

\subsection{Digital mapping}

The main geometrical components recorded through structural mapping are orientation, spacing, size and intensity of fractures (Dershowitz \& Einstein 1988). Digital or 'virtual' structural mapping was conducted on the DTM using the 3DM Analyst. The fracture traces were visually identified on the images. Points were selected on the identified traces. The orientation of the fracture planes was computed within the 3DM Analyst and represented by a 3D circle on the rock face. The results are presented in Figure 3. All fractures are defined by their centre coordinates, trace lengths and orientation. 


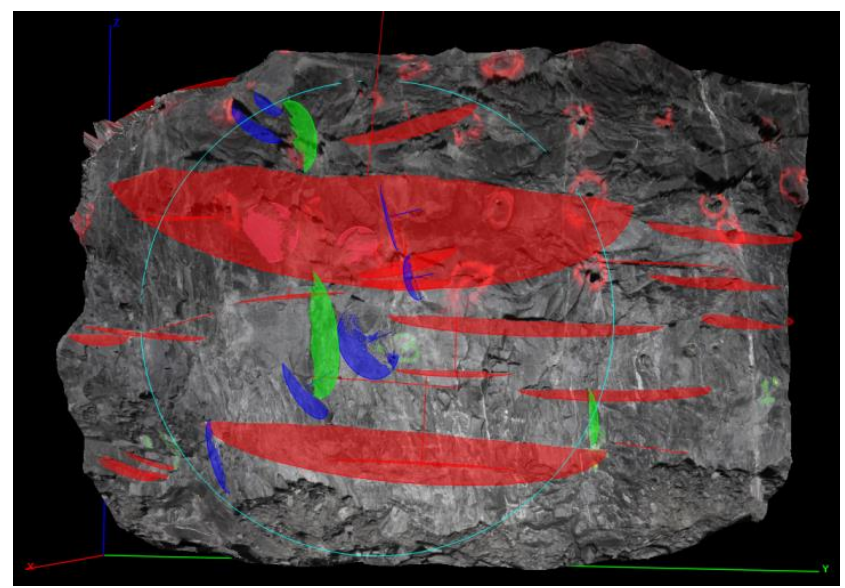

(a)

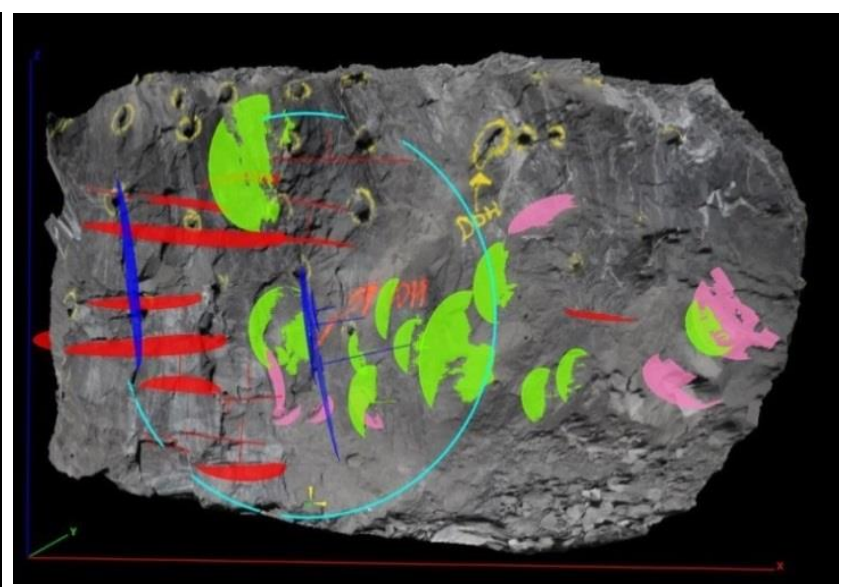

(b)

Figure 3 (a) Amn-0354 3D face model with major discontinuity sets mapped using a $2 \mathrm{~m}$ radius mapping window; (b) Gmn-0357-1n 3D face model with major discontinuity sets mapped using a $2 \mathrm{~m}$ radius mapping window

\subsection{Fracture orientation}

All identified fractures in the 3DM Analyst were exported to Dips (Rocscience 2011). In all, four dominant joint sets were identified from the stereonet plots. The mean orientations were determined for each joint set and the dispersion around the mean orientation values was quantified using the Fisher distribution (Brady \& Brown 2004).

\subsection{Fracture trace length}

Trace length (or persistence) sampling is susceptible to four major biases (Zhang \& Einstein 1998): orientation bias, size bias, truncation bias, and censoring bias. In this investigation, fracture trace lengths were determined from the constructed models using the sampling approach proposed by Zhang and Einstein (1998). This approach minimises bias and allows for a non-biased estimation of trace lengths for all joint sets. The non-biased trace length estimator $\mu$ was calculated using Equation 1.

$$
\mu=C \frac{\pi\left(N+N_{0}-N_{2}\right)}{2\left(N-N_{0}+N_{2}\right)}
$$

where:

$C=$ radius of the circular sampling window.

$N=$ total number of traces intercepting the window.

$N_{0}=$ number of traces with two extremities contained within the sampling window.

$N_{2}=$ number of traces with two extremities lying outside of the sampling window.

In the Éléonore case study, the mapping window radius was selected to maximise its size at the rock face. The maximum traces sampled on the faces were also evaluated. Random fractures were ignored due to their low occurrence (less than $5 \%$ of the mapped fractures). Fracture trace length was relatively small with a mean value around $1 \mathrm{~m}$ or less. This would classify these joint sets as low to very low persistence based on Brady and Brown (2004).

\subsection{Fracture intensity}

Fracture intensity can be calculated by several qualitative and quantitate techniques. In this paper, in order to maximise the surface information available from the digital images, fracture intensity was calculated for every joint set based on the summation of trace lengths per unit area (P21), as defined by Mauldon and 
Dershowitz (2000). The fracture intensity for joint set 1 was considerably higher than those of the other three joint sets.

\subsection{Summary of fracture properties}

The fracture properties obtained through the photogrammetry campaign at Éléonore are presented in Table 1. These structural properties were deemed adequate to represent the metasomatised greywacke on level 440 at the mine. The use of photogrammetry expedited the data collection process in an operating mine and provided the input data for the subsequent analysis.

Table 1 Fracture properties based on the photogrammetry campaign

\begin{tabular}{lcccc}
\hline Joint set & $\mathbf{1}$ & $\mathbf{2}$ & $\mathbf{3}$ & $\mathbf{4}$ \\
\hline Mean dip/dip direction $\left({ }^{\circ}\right)$ & $06 / 056$ & $87 / 135$ & $80 / 0090$ & $67 / 024$ \\
Fisher's K constant & 52 & 29 & 58 & 16 \\
Unbiased trace length $(\mathrm{m})$ & 1.20 & 0.90 & 0.46 & 0.60 \\
Maximum trace $(\mathrm{m})$ & 4.70 & 2.00 & 1.95 & 0.70 \\
$\mathrm{P}_{21}$ & 1.40 & 0.47 & 0.21 & 0.26 \\
\hline
\end{tabular}

\section{DFN modelling}

Several conceptual models can be used for the generation of DFN. Staub et al. (2002) provided an excellent review of available models. Most of the proposed models are available in proprietary or commercially available software packages. For generating fracture system models for the Éléonore Project, the authors employed a software package, Fracture-SG, which incorporates, among others, both the Veneziano and the Baecher model (Grenon \& Hadjigeorgiou 2008). The interest in these two models is that the required input parameters can be easily inferred from field data.

The Veneziano model, described by Dershowitz and Einstein (1988), relies on the generation of a Poisson network of planes in 3D space followed by a secondary process of tessellation by a Poisson line process and marking of polygonal fractures. The use of the Veneziano model results in polygonal shape fractures. It is also implied that fractures produced on the same plane during the primary generation process remain coplanar after the secondary tessellation process. These are the main limitations of the model. In this paper, a modified version of the Veneziano model, which enabled translation of coplanar joints, was used (Grenon \& Hadjigeorgiou 2012). The Baecher model (Baecher et al. 1978) relies on the generation of polygon centres randomly located in the generation volumes. Polygon orientation and area are then generated.

The forward modelling technique was used to calibrate the generated fracture systems. In this case study, several DFN generations were necessary in order to achieve statistical agreement between the modelling results and the field data obtained using photogrammetry. Scan planes were introduced in the DFN and the fracture properties on these planes were compared to photogrammetry results. A typical calibrated DFN with a volume of $20 \times 20 \times 20 \mathrm{~m}$ had more than 18,000 fractures. To validate the DFN models, scan planes with the same orientation as the underground rock faces were simulated through the models. The intercepted fractures along these scan planes were calibrated until a good agreement was observed for mean orientation and dispersion for every set. Fractures were then also calibrated for their mean trace lengths. Seven scan planes were introduced within every model, each containing five randomly located circular sampling windows - with a radius equal to the radius for the photogrammetry analysis - to sample the fractures.

The DFN models were adjusted until a satisfactory statistical agreement was achieved between field and model data. Fracture intensities ( $P_{21}$ : total trace length of fractures per unit area) were then calibrated until 
satisfactory agreement was reached. The whole calibration process was greatly facilitated by enabling easy direct comparisons between field information provided by photogrammetry and generated fractures.

\section{$4 \quad$ DFN and drift structural stability}

DFN modelling can be used for several applications in underground mines. The focus of this paper is the identification of structural wedges formed along mining drifts. In the early stages of mining at the Éléonore Project, during development of the drifts, the formation of structurally defined wedges was observed on a few occasions. Wedge instability along the walls was a concern at times.

Dershowitz and Einstein (1988) suggested that the Veneziano model usually does not tend to produce blocks unless the joints are $100 \%$ persistent and unbounded. However, previous work by the authors aimed at investigating the stability of wedges on rock slopes and tunnels (Grenon \& Hadjigeorgiou 2012; 2008; Hadjigeorgiou \& Grenon 2005) using a modified Veneziano model to generate DFN, demonstrated the ability of such a model in producing wedges. In the present work at Éléonore, both the Baecher and Veneziano models were used to investigate the creation of wedges on the walls and the roof of typical mining drifts.

\subsection{Wedge analysis around a typical mining drift}

Once a DFN model was constructed and calibrated the drift was introduced in the rock mass. The first step of the analysis was to investigate the formation of wedges along a $17 \mathrm{~m}$ long drift using the Baecher model. Figure 4 illustrates the wedges formed along the drift for one specific DFN. Recognising the stochastic nature of DFN, and in order to fully capture possible wedge formation, a total of 120 DFN models were generated (almost $2 \mathrm{~km}$ of drift). For all cases, two drifts were inserted within every DFN. The need for multiple simulations, however, is sometimes overlooked in some of the technical literature.

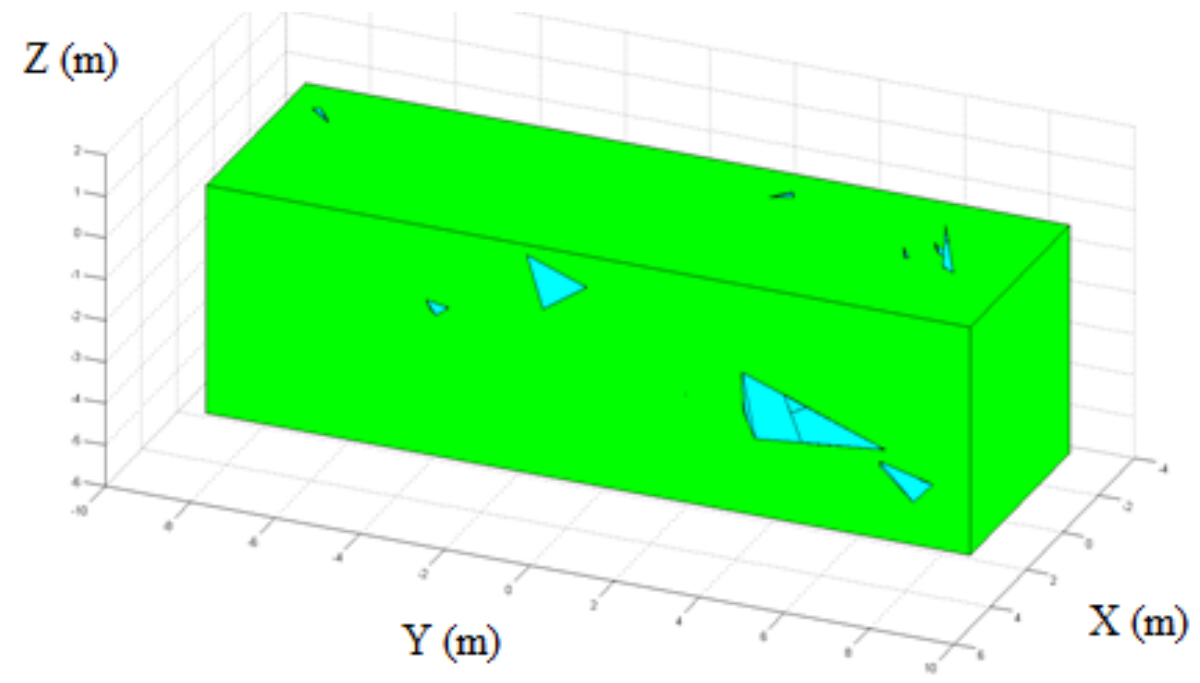

Figure 4 Illustration of wedge generated for the max fracture representation along a $17 \mathrm{~m}$ drift

The structurally defined rock wedges along the walls and backs of each drift were determined for the 120 generated DFN. Table 2 summarises the results for this typical drift. Only a relatively small number of wedges were created along the drift. Wedge type instability does not seem to pose a real major concern for these drifts, given the size of the wedges (maximum $0.070 \mathrm{~m}^{3}$ ). The inherent assumption is that the generated DFN models capture the complexity of the rock mass. 
Table 2 Wedge properties for 240 drifts within 120 DFNs

\begin{tabular}{lc}
\hline & DFN input (Baecher model) \\
\hline Total number of wedges & 1,772 \\
Mean number of wedges per drift & 7.8 \\
Maximum volume $\left(\mathrm{m}^{3}\right)$ & 0.070 \\
Volume 99th percentile $\left(\mathrm{m}^{3}\right)$ & 0.012 \\
Volume 95th percentile $\left(\mathrm{m}^{3}\right)$ & 0.0026 \\
Volume 90th percentile $\left(\mathrm{m}^{3}\right)$ & 0.0010 \\
\hline
\end{tabular}

\subsection{Impact of variability in input data for the analysis}

In most cases the input parameters used for a DFN analysis consist of a mean value and its corresponding distributions. Recognising that the structural information was obtained from a relatively small sample, which is often the case in mining projects, it was decided to further investigate the impact of variations in the input data on the generation of rock wedges along the excavation.

Three scenarios of input data variability were investigated in generating DFN using the Baecher model with 120 generations each. The first case used the in situ properties determined from mapping (mean), the second case employed the maximum trace length for the mean value, but at the same time keeping the P32 value constant (max). Finally, the third scenario used the maximum trace length as the mean value and increased P32 (worst). The last scenario results in a heavily jointed rock mass. Both the mean and max simulations were based on the same total fracture area over the entire simulated volume. Max and worst simulations employed the same fracture size distributions to generate the DFN. Figure 5 is an example of the generated DFN for joint set 1 using the three approaches (mean, max and worst).
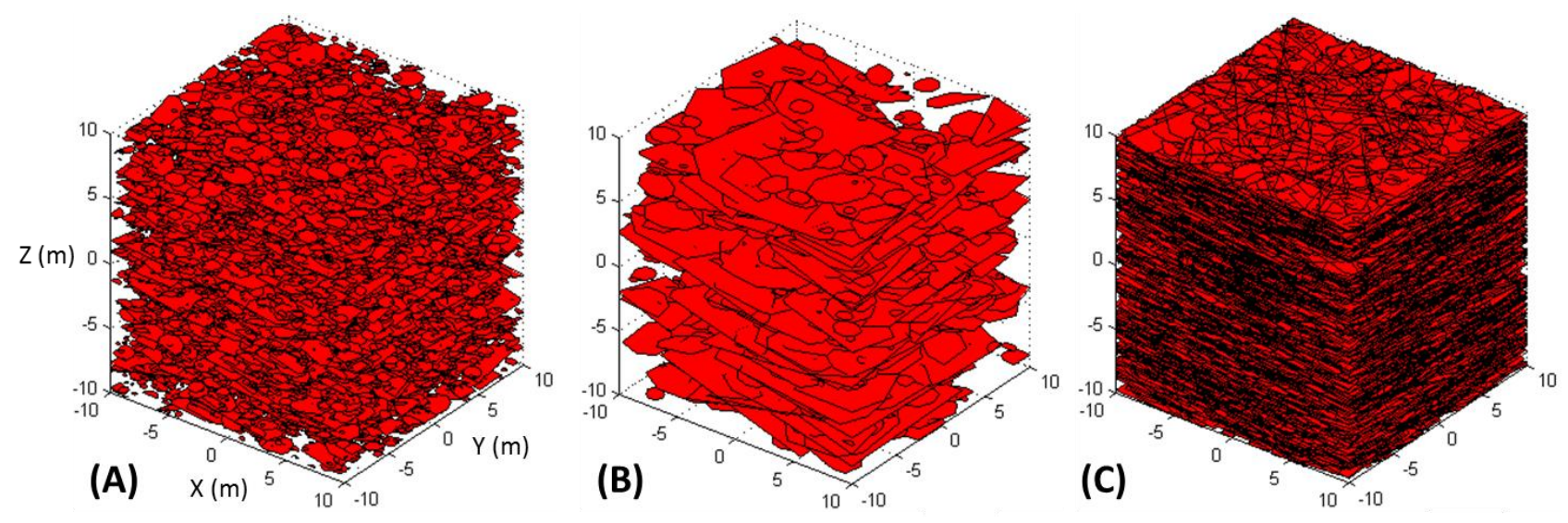

Figure 5 DFN for set 1 using (a) mean fracture representation, (b) max fracture representation and (c) worst fracture representation using a Baecher model

Table 3 summarises the characteristics of all generated rock wedges, along the walls and back of the drift, for the three DFN input scenarios. The mean number of wedges formed along each drift is the average, determined from two drifts in the 120 DFN simulations. There is a significant variation in the results between the three series of simulations. Of interest is that the simulations that used the mean and worst input data vary significantly, even though the same P32 was used. This demonstrated that P32, in itself, cannot be the only parameter used for characterising a given rock or structural regime. The results from the Worst case demonstrated that both P32 and fracture size have a critical impact in wedge formation along the drift. 
Table 3 Wedge properties for the three investigated DFN inputs

\begin{tabular}{lccc}
\hline & \multicolumn{3}{c}{ DFN input } \\
& Mean & Max & Worst \\
\hline Number of wedges & 1,772 & 4,870 & $2,665,348$ \\
Mean number of wedges per drift & 7.8 & 20.3 & $11,105.6$ \\
Maximum volume $\left(\mathrm{m}^{3}\right)$ & 0.070 & 1.40 & 20.6 \\
Volume 99th percentile $\left(\mathrm{m}^{3}\right)$ & 0.012 & 0.29 & 0.42 \\
Volume 95th percentile $\left(\mathrm{m}^{3}\right)$ & 0.0026 & 0.06 & 0.10 \\
Volume 90th percentile $\left(\mathrm{m}^{3}\right)$ & 0.0010 & 0.03 & 0.044 \\
\hline
\end{tabular}

Figure 6 illustrates the cumulative volume plot of wedges formed around the drift. This graph can be used to assess the critical, by volume, wedge that might be encountered around the drift. This knowledge can be put in good use when developing an appropriate reinforcement strategy such as bolting pattern and rockbolt length. For example, a reinforcement rockbolting pattern can be selected to ensure that $95 \%$ of possible wedges could be secured by the standard bolt pattern. The remaining $5 \%$ of potentially unstable wedges could be stabilised by additions to the standard bolting pattern.

\subsection{Impact of the number of simulations}

In reviewing the form of the plots in Figure 6 it was recognised that the worst scenario line is smooth, while the two others are step-like. This is related to the number of wedges generated. A fundamental question in this type of analysis is, however, what number of simulations is necessary to ensure that all possible wedges are captured by the models.

To investigate the impact of the number of DFN on the resulting wedges, 120 DFN models were created using the max properties defined in Section 4.2. The wedges formed along the wall of a drift, within each DFN, are presented in Table 4. The first observation is that the total number of wedges is steadily increasing with more simulations. The number of wedges per DFN remains relatively constant. The maximum volume for a wedge along the drift was $1.37 \mathrm{~m}^{3}$ and was reached after 60 simulations. It is understood that a single wedge of a larger volume could be generated after a greater number of other DFN generations. Of interest for design purposes is the volume of wedges associated to high percentile values (percentile >99th percentile for example). It can be observed that a constant wedge volume is reached after 40 simulations for high percentile values. This is the number of simulations that would appear to be adequate for this specific problem.

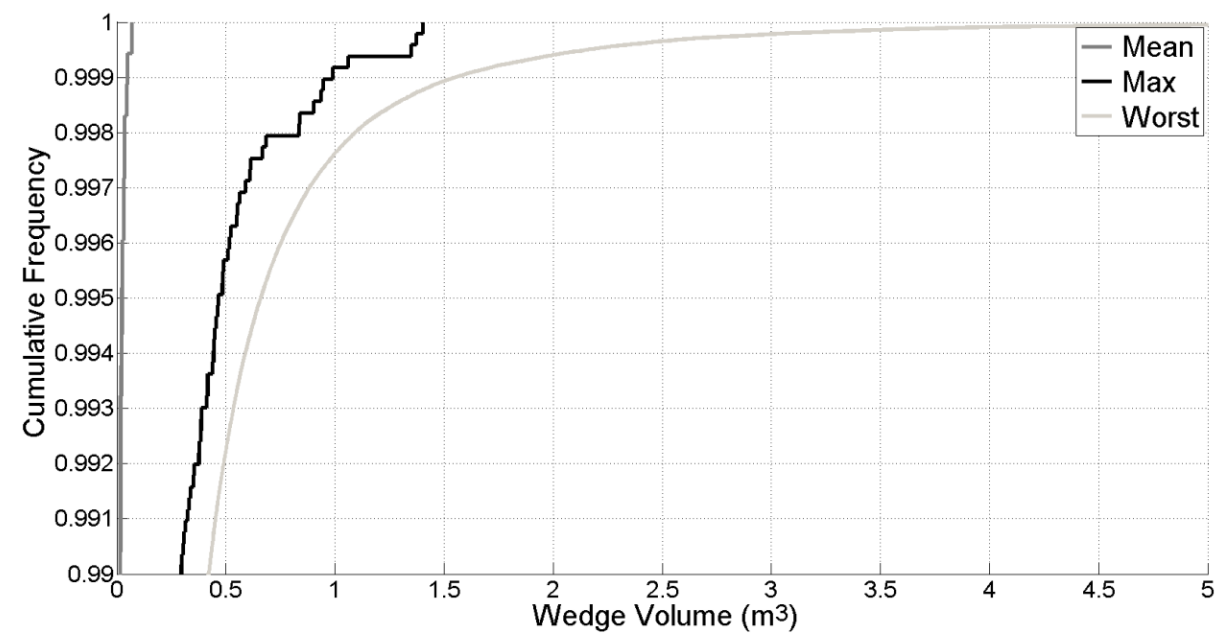

Figure 6 Wedge volume distribution along two $17 \mathrm{~m}$ drift for 120 DFN models for three input types 
Table 4 Cumulative Wedge properties for various number of DFN simulations

\begin{tabular}{l|cccccc}
\hline Number of DFN simulations & 20 & 40 & 60 & 80 & 100 & 120 \\
Number of wedges & 346 & 739 & 1124 & 1506 & 1892 & 2266 \\
Number of wedges per DFN & 17.3 & 18.5 & 18.7 & 18.8 & 18.9 & 18.6 \\
Maximum volume $\left(\mathrm{m}^{3}\right)$ & 1.06 & 1.06 & 1.37 & 1.37 & 1.37 & 1.37 \\
Volume 90th percentile $\left(\mathbf{m}^{3}\right)$ & 0.0345 & 0.0276 & 0.0338 & 0.0345 & 0.0350 & 0.0304 \\
Volume 95th percentile $\left(\mathbf{m}^{3}\right)$ & 0.0657 & 0.0669 & 0.0785 & 0.0889 & 0.0836 & 0.0784 \\
Volume 99th percentile $\left(\mathbf{m}^{3}\right)$ & 0.3582 & 0.3780 & 0.3974 & 0.3884 & 0.4129 & 0.3881 \\
Volume 99.5th percentile $\left(\mathbf{m}^{3}\right)$ & 0.5499 & 0.5560 & 0.5568 & 0.5279 & 0.5334 & 0.5142 \\
Volume 99.9th percentile $\left(\mathbf{m}^{3}\right)$ & 0.8856 & 1.0094 & 1.0529 & 1.0259 & 0.9986 & 0.9782 \\
\hline
\end{tabular}

\subsection{Comparing Baecher and Veneziano generated DFN models}

A discussion that appears to be missing in DFN applications in mining is the impact of the selected model on the engineering analysis. In theory, several DFN models can be used to represent the structural conditions at a given site. Successfully calibrated DFN can provide good statistical agreement with field data and the conclusion is inferred that the models are acceptable. Nevertheless, the various DFN models can have considerably different geometrical characteristics. Figure 7 is an illustration of a calibrated model for joint set 2 at the Éléonore mine, using both the Veneziano and Baecher models. This particular fracture set is characterised by relative low fracture intensity. The geometrical characteristics of the models are visually quite dissimilar. Consequently, the number of wedges along a drift excavated in these DFN could be different. This is demonstrated in Figure 8.

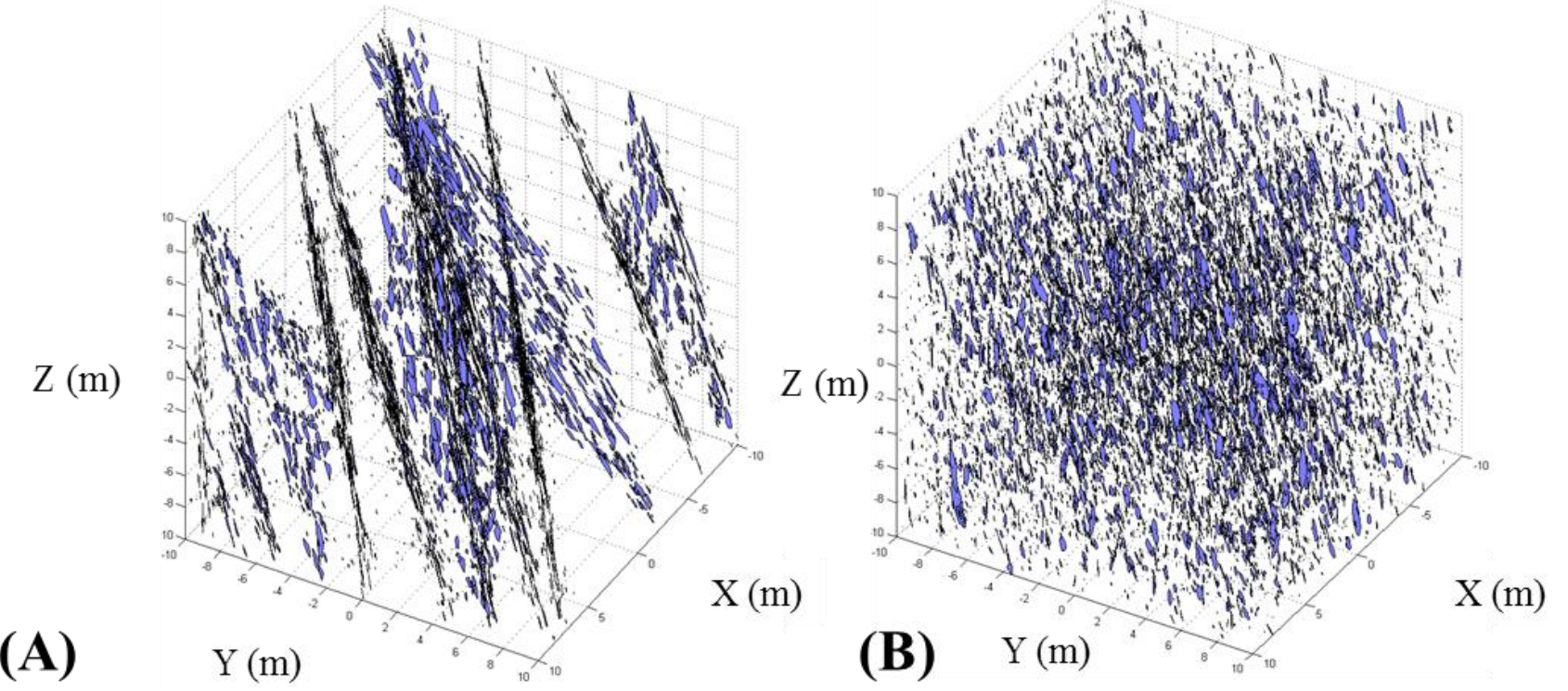

Figure 7 Visual comparison between the DFN representations of joint set 2 generated using the Veneziano model (A) and the Baecher model (B)

Figure 8 illustrates the volume of wedges along the walls of a horizontal drift at Éléonore. The top part of these graphs illustrates the wedges formed along the walls of the drift, using DFN generated by the Veneziano and Baecher models. The main point is that these are different for this particular rock mass. The two lower graphs in Figure 8 are scatter plots of all wedges formed along the walls of the drifts. The graph further illustrates the wedges formed as a result of the interaction of the different joint sets. In effect, it 
shows the joint set associated with the 3 faces of a wedge. A limit equilibrium analysis was conducted for each wedge, and wedges with a Factor of Safety $>1$ are indicated as stable in Figure 8.

The practical implications for this particular analysis is that the DFN generated using the Veneziano model for this drift configuration resulted in the formation of smaller wedges with none of them exceeding a weight greater than $1 \mathrm{t}$. On the other hand, the analysis based on the Baecher generated DFN resulted in a considerably greater number of wedges, both stable and unstable. This example clearly demonstrates the possible impact of the choice of DFN model on the structural stability of a drift. In this example, use of the Veneziano generated DFN results in smaller wedges that are less of a concern for stability purposes. The results can be explained by the fact that low P32 values associated with small fracture size may be less prone to creation of wedges locally than the more uniform fracture distribution in the Baecher model. To the authors knowledge the influence of the DFN model in the results is often overlooked or ignored. For engineering purposes, it is necessary to ensure that the generated DFN model is representative of the field conditions. At the Éléonore case studies, the Baecher model was more appropriate. In effect, the field observations did not support the presence of strong joint coplanarity as required by the Veneziano model.
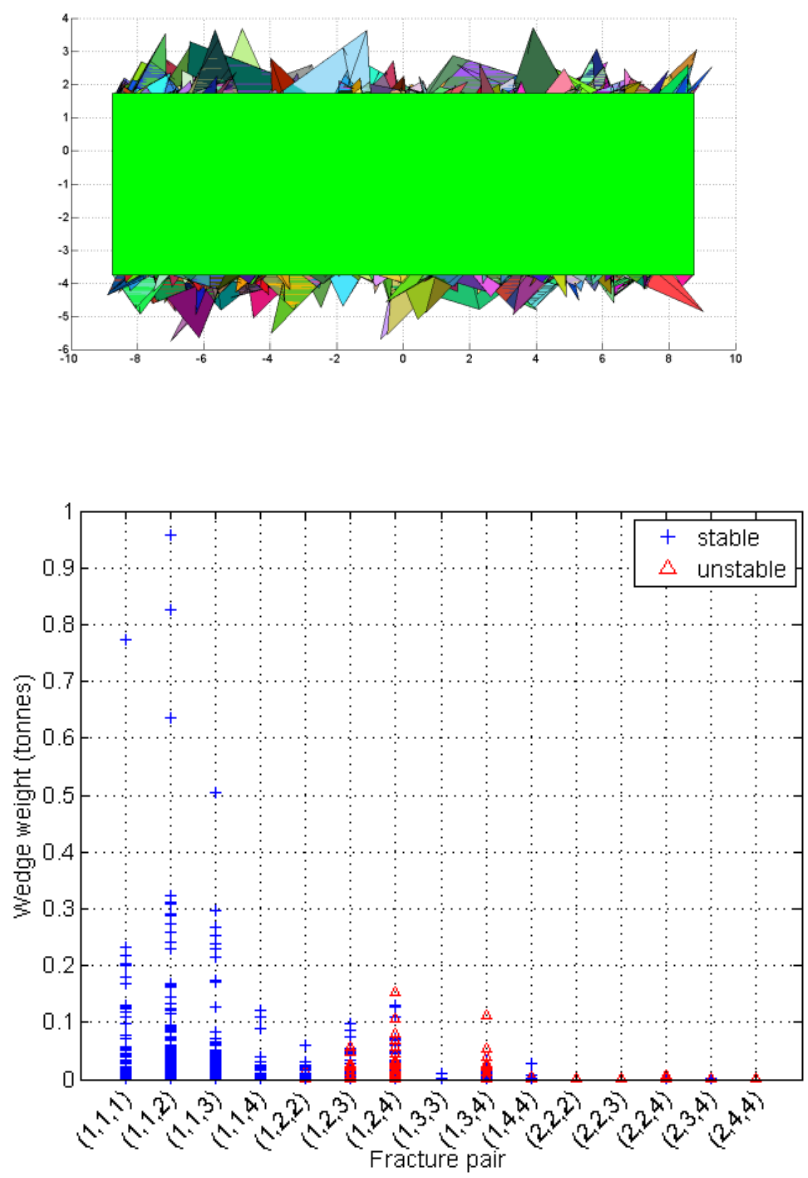

(a)
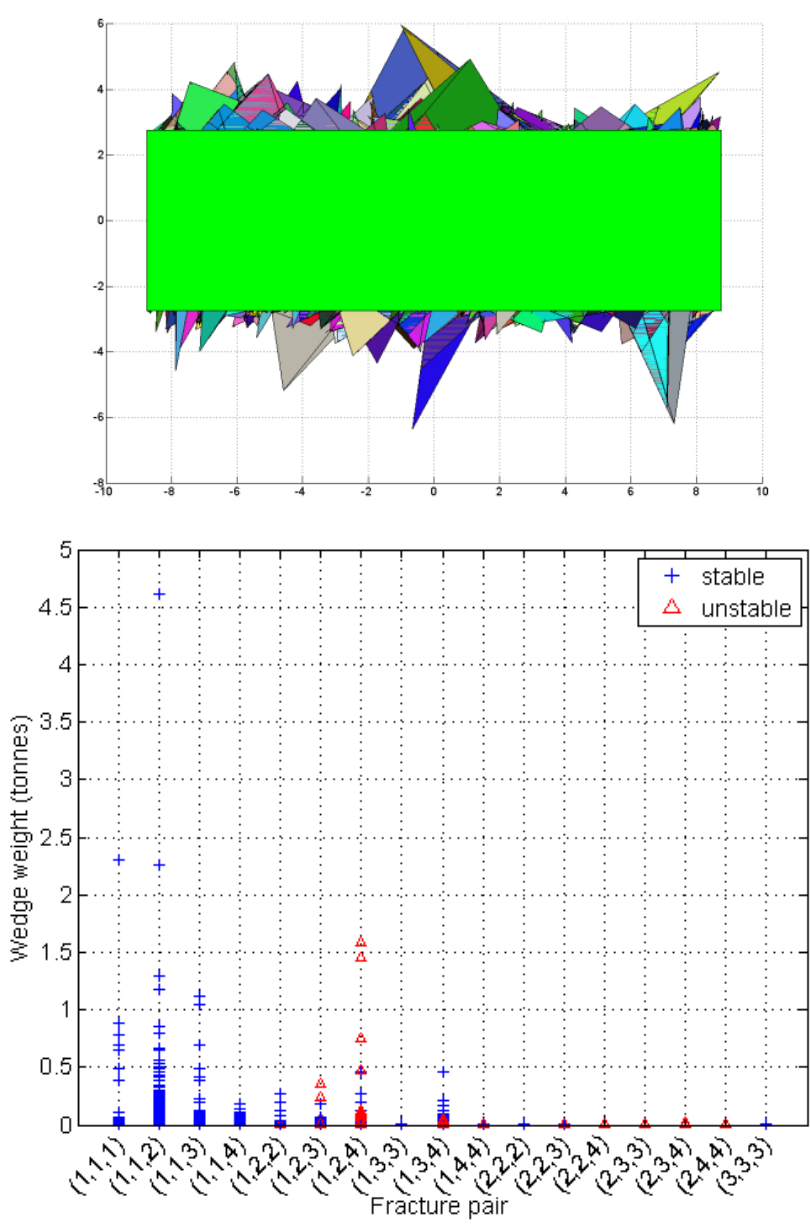

(b)

Figure 8 Wedge formation on the walls of a horizontal drift using (a) a Veneziano model and (b) a Baecher model. Above graphs show DFN generated using (a) the Venniziano model and (b) the Baecher model

\section{Conclusion}

The use of DFN provides an additional tool in investigating the stability of underground mining drifts. This paper highlights important issues that have to be taken into consideration in order for the method to reach its full potential. The use of photogrammetry addresses some of the issues associated with data collection 
to ensure that the necessary input is available to generate DFN models. At the Éléonore mine, photogrammetry was successfully employed to quantify the structural regime at three rock faces. The results from a photogrammetry data collection campaign were used to provide input for DFN modelling at the site. The availability of this data facilitated the calibration of these DFN models. A case study was presented of generating DFN models, and investigating their use as part of a stability investigation, for mining drifts at the Éléonore mine.

The impact of variations in the input data was explored by considering three different scenarios. These examples are not extreme, but can easily result as part of the assessment of the structural regime. This is demonstrated by the fact that the use of similar P32 as input does not result in similar wedge conditions.

The second issue was the number of simulations DFN needed to capture the full range of wedges. It is understood that the maximum size wedge could arise at any given simulation, but volume obtained for high percentile values (above 99\%) are reaching a plateau after a relative low number of DFN simulation. This paper demonstrated that, given that DFN are stochastic, it is necessary to undertake multiple simulations. This is critical in gaining confidence in the results.

The third issue in the use of DFN is the choice of model. In the case study at the Éléonore mine site, two conceptual models, Baecher and modified Veneziano, were tested to generate the DFN models. Although both models were validated and considered statistically acceptable, the resulting rock masses were different. This can have a clear impact on the generated rock wedges and stability of underground mining drifts.

\section{Acknowledgement}

The authors acknowledge the financial support of Mitacs, FRQNT and Goldcorp Éléonore. The collaboration of mining personnel at Goldcorp's Éléonore operation is acknowledged.

\section{References}

ADAM Technology 2010, 3DM Analyst Mine Mapping Suite 3D measurement, camera calibration and block adjustment software user guide draft, ADAM technology, Perth.

Birch, JS 2006, 'Using 3DM Analyst Mine Mapping Suite for rock face characterization', in F Tonon \& J Kottenstette (eds), Proceedings of the Laser and Photogrammetric Methods for Rock Face Characterization Workshop, American Rock Mechanics Association, Minneapolis, $15 \mathrm{p}$.

Brady, BHG \& Brown, ET 2004, Rock Mechanics for Underground Mining, 3rd edn, Kluwer Academic Publishers, Netherlands.

Dershowitz, WS \& Einstein, HH 1988, 'Characterizing rock joint geometry with joint system models', Rock Mechanics and Rock Engineering, vol. 21, no. 1, pp. 21-51.

Dubois, É \& Grenon, M 2012, 'Caractérisation structurale à l'aide de la photogrammétrie: mine Kikialik, Nunavik, Québec', in A Rancourt (ed.), Proceedings of Tunnels and Underground Spaces: Sustainability and Innovation. Tunnelling Association of Canada, Montreal.

Gaich, A, Pötsch, M \& Schubert, W 2006, 'Basics, principles and application of 3D imaging systems with conventional and high-resolution cameras', in DP Yale (ed.), Proceedings of the 41st US Symposium on Rock Mechanics (USRMS), American Rock Mechanics Association, Minneapolis.

Gaich, A, Pötsch, M \& Schubert, W 2008, 'Computer vision for rock mass characterization in underground excavation', in F Tonon (ed.), Proceedings of the 42nd US Rock Mechanics Symposium, American Rock Mechanics Association, Alexandria, VA, 14 p.

Golder Associates 2008, Éléonore project site investigation report: geotechnical study for the underground mine, internal report, Golder Associates. Golder Associates, Montreal.

Grenon, M \& Hadjigeorgiou, J 2008, Fracture-SG: a fracture system generator software package, version 2.17.

Grenon, M \& Hadjigeorgiou, J 2012, 'Applications of fracture system models (FSM) in mining and civil rock engineering design', International Journal of Mining, Reclamation and Environment, vol. 26, no. 1, pp. 55-73.

Grenon, M, Lemy, F \& Hadjigeorgiou, J 2004, 'Fracture system modeling based on input data from traditional mapping and image analysis', in W Schubert (ed.), Proceedings of EUROCK 2004 \& the 53rd Geomechanics Colloquium, pp. 445-448.

Hadjigeorgiou, J \& Grenon, M 2005, 'Design of ventilation raises in hard rock mines', in DP Yale (ed.), Proceedings of the 40th US Symposium on Rock Mechanics (USRMS), American Rock Mechanics Association, Minneapolis.

Haneberg, WC 2008, 'Using close range terrestrial digital photogrammetry for 3-D rock slope modeling and discontinuity mapping in the United States', Bulletin of Engineering Geology and the Environment, vol. 67, no. 4, pp. 457-469. 
Kemeny, J, Turner, K \& Norton, B 2006, 'LiDAR for rock mass characterization: hardware, software, accuracy and best-practices', in F Tonon \& J Kottenstette (eds), Proceedings of the Laser and Photogrammetric Methods for Rock Face Characterization Workshop, American Rock Mechanics Association, Minneapolis.

Kulatilake, PHSW \& Wu, TH 1984, 'Estimation of mean trace length of discontinuities', Rock Mechanics and Rock Engineering, vol. 17 , no. 4, pp. 215-232.

Lajoie, P-L 2013, 'Mise en production d'Éléonore avec ses différents défis géomécaniques', Proceedings of Québec Mine, Quebec City, http://quebecmines.gouv.qc.ca/2013/programme/conferences.asp

Mauldon, M \& Dershowitz, W 2000, 'A multi-dimensional system of fracture abundance measures', Proceedings of the 112th Annual Meeting of the Geological Society of America (Summit 2000), Geological Society of America, Boulder, CO.

Ministère de l'Énergie et des Ressources naturelles du Québec 2011, Projet Éléonore: Développement durable: le point de vue industriel et l'expérience du projet aurifère Éléonore, viewed 11 June 2014, http://www.mern.gouv.qc.ca/mines/quebecmines/2011-03/31mai/pm/5-guay.pdf

Pahl, PJ 1981, 'Estimating the mean length of discontinuity traces', International Journal of Rock Mechanics and Mining Sciences \& Geomechanics Abstracts, vol. 18, no. 3, pp. 221-228.

Priest, SD 1993, Discontinuity analysis for rock engineering, 1st edn, Chapman \& Hall, London.

Priest, SD \& Hudson, JA 1976, 'Discontinuity spacing rock', International Journal of Rock Mechanics and Mining Sciences, vol. 13, no. 5 , pp. $135-148$.

Rocscience 2011, Dips v. 6.012 software information, Rocscience Inc., Toronto, ON.

SRK Consulting 2011, Structural model of the Éléonore deposit, Quebec, internal report, SRK Consulting, Perth.

Staub, I, Fredriksson, A \& Outters, N 2002, Strategy for a rock mechanics site descriptive model development and testing of the theoretical approach, SKB report, no. R-02-02, prepared for Golder Associates AB, Stockholm.

Sturzenegger, M \& Stead, D 2009, 'Close-range terrestrial digital photogrammetry and terrestrial laser scanning for discontinuity characterization on rock cuts', Engineering Geology, vol. 106, no. 3-4, pp. 163-182.

Sturzenegger, M, Stead, D, Beveridge, A, Lee, S \& van As, A 2009, 'Long-range terrestrial digital photogrammetry for discontinuity characterization at Palabora open-pit mine', in M Diederichs \& G Grasselli (eds), Proceedings of the Third Canada-US Rock Mechanics Symposium and the 20th Canadian Rock Mechanics Symposium (RockEng09), $10 \mathrm{p}$.

Zhang, L \& Einstein, HH 1998, 'Estimating the mean trace length of rock discontinuities', Rock Mechanics and Rock Engineering, vol. 31, no. 4, pp. 217-235. 